\title{
Realization of the Speech Acts of Request and Apology by Middle Eastern EFL Learners
}

\author{
Yaseen Alzeebaree ${ }^{1,2,3^{*}}$, Mehmet Ali Yavuz ${ }^{1}$ \\ ${ }^{1}$ Cyprus International University, Faculty of Education, Department of English Language, Nicosia, N. CYPRUS \\ ${ }^{2}$ Akre Branch - English Language Teaching Department, Rawanduz Private Technical Institute, Akre City, Kurdistan Region, IRAQ \\ ${ }^{3}$ Nawroz University, College of Languages, Department of English, IRAQ
}

Received 19 June 2017 - Revised 5 September 2017 • Accepted 6 October 2017

\begin{abstract}
The objective of this study was to investigate the request and apology strategies of Kurdish EFL undergraduate students (KEFLUS) and their linguistic and pragmatic competence in making requests and apologies. The participants were 83 KEFLUS and 14 native speakers of English (NSE). A Discourse Completion Task (DCT) and rating scale developed by the researcher were used to collect the data. After the responses were collected, the data were coded and analysed according to the taxonomy of BlumKulka et al. (1989) Cross-Cultural Speech Acts Realization Patterns (CCSARP) for request and the Olshtain and Cohen (1983) taxonomy for apology. Furthermore, the collected data were rated by four researchers. The results of the study revealed the differences in responses between the KEFLUS and NSE groups and between the state and private universities. However, no significant difference was found between KEFLUS males and females. Moreover, the KEFLUS responses were in general pragmatically and structurally appropriate.
\end{abstract}

Keywords: apology, pragmatic competence, request, speech act theory

\section{INTRODUCTION}

English language is becoming more important as a universal means of communication, particularly after the recent advances in technology that have brought people of different cultures and countries closer to one another. The success of achieving one's goals depends to some degree on communicative competence. Furthermore, deficiencies in communicative competence can sometimes lead to many societal problems and misunderstandings. Pragmatic failure may occur when people are not sufficiently competent (Thomas, 1983) or when there is a communicative breakdown (Jia, 2007). Traditionally, learning a language means learning a structure. Most learners spend time and effort in acquiring the linguistic rules while neglecting the social and cultural aspects of language learning.

\section{PRAGMATIC COMPETENCE}

Pragmatic competence refers to the ability to communicate properly in a social situation. It is a key aspect in communicative competence. It needs the knowledge of Pragmalinguistics, how to make speech acts, like apology, complaint, etc. in a certain language, and sociopragmatics, knowledge about how to use such speech acts in appropriate situations. The interaction of pragmalinguistic aspects and sociopragmatic elements is significant in intercultural communication where the participants have usually had more access to pragmalinguistics than to sociopragmatics, particularly if the target language acquisition occurs in the classroom. This presumes that L2 learners frequently have more pragmalinguistics competence than sociopragmatics (Kecskes, 2014).

\section{SPEECH ACTS THEORY}

A speech act refers to an act uttered and performed by a speaker (Searle et al., 1980), such as making statements, asking questions, giving orders, thanking, etc. Austin (1962) first developed and introduced the concept of the 


\section{Contribution of this paper to the literature}

- An analysis of the students' responses demonstrates that private universities students are more competent in terms of sociopragmatics and pragmalinguistics than state universities.

- EFL/ESL teachers should pay more attention to pragmatic knowledge and raise student awareness of English socio-cultural norms of speech act realizations.

- Rating scale can be used as an important instrument to measure the appropriacy of pragmatic and linguistic forms.

speech act. Speech acts can be one word or more (e.g., Pardon) or sentences (I'm sorry for being late. I forgot your book) or gestures and body movement performed directly or indirectly that serve a function in communication (Hatch, 1992). Speech acts are regarded as the functional aspects of language. Austin (1975) claimed that people do things with their words as well. Speech acts can be split into constative and performative utterances. The former is used to state or describe something and is judged in terms of truth and falsity, whereas the latter is used to do something, or to perform an action and is judged as either happy (felicitous) or unhappy (Austin, 1962). Speech acts mirror the culture and social norms of the language. Therefore, the lack of such cultural, social, and pragmatic context and norms in communication may cause misunderstandings and pragmatic failure. Austin (1965) stated that an utterance involves three types of linguistic acts: the locutionary act (what is said), the illocutionary act (what is meant) and the perlocutionary act (the effect on the hearer).

Some cross-cultural studies have been conducted focusing on the performance of the speech acts (requests and apologies) comparing and contrasting native and non-native speakers of English. Among these studies is that undertaken by Blum-Kulka and Olshtain (1984) which examined the issue of universality in pragmatics through cross-cultural perspectives using Discourse Completion Tests. The study revealed differences between the two groups in their request and apology strategies.

\section{Speech Acts of Request}

Requests are useful and happen often in everyday speech acts, particularly among new learners of language. Communications often start with a request. Compared to other types of speech acts, the illocutionary act of requests has been the most frequently researched in second language studies. Requests are expressed by different linguistic structures (e.g., declaratives, interrogatives or imperatives), and for a variety of purposes or aims. A request is a face-threatening act. A speaker needs to follow some strategies to lessen or alleviate causing offence (Achiba, 2003).

Searle argued that among the five speech act types (representatives, directives, commissives, expressives, and declarations), directives, i.e., "attempts by the speaker to get the hearer to do something" (Searle, 1976: 11), are the most frequently studied. The verbs used in this category, according to him, are 'ask', 'order', 'command', 'request', 'beg', 'plead', 'pray' and 'entreat', as well as 'invite', 'permit', and 'advise'.

The concept of indirectness and politeness has a great influence on face in the realization of speech acts such as requests. Indirectness on the part of the speaker is preferred for certain reasons, for example, to lessen and mitigate the threat, to avoid the risk of losing face or to smooth the conversational interaction. It has been noticed that higher levels of indirectness may lead to higher levels of politeness. Brown and Levinson (1987) maintained that requests are face-threatening acts since they threaten the addressee's negative face. Trosborg stated that the requester exercises power and control over the requestee and in doing so threatens the requestee's negative face (the desire to be unimpeded). Moreover, a request is an impositive act performed by the speaker to impact on the intentional behavior of the hearer for the benefit of the former only and at the cost of the latter. Conversely, a suggestion is defined as being of use for both interlocutors, the speaker and the hearer (Trosborg, 1995).

\section{Request Categories and Strategy Classification}

Based on the speech act theory, there are two strategies (direct and indirect) used to achieve the same speech act. The former is defined as utterances in which there is consistency between the propositional content (sentence meaning) and the speaker's intent (speaker meaning) of an utterance (Holtgraves, 1986), whereas the latter is an utterance in which the speaker's meaning and the propositional content are not identical. Therefore, direct strategies carry only one meaning or illocutionary force; on the other hand, indirect strategies have more than one meaning (Clark, 1979).

The strategies used to request, based and built on previous studies, particularly on those of Austin (1962) and Searle (1969) as revised by Brown and Levinson (1978, 1987), House and Kasper (1987), and Blum-Kulka and Olshtain (1984), were classified by Trosberg (1995) into four forms: (1) direct, (2) conventionally indirect (hearerbased), (3) conventionally indirect (speaker-based), and (4) indirect. The realization of these strategies is presented in Table 1 with regard to a situation in which the speaker requests to borrow the hearer's car. 
Table 1. Taxonomy of request realization strategies (Trosborg, 1995: 205)

\begin{tabular}{|c|c|c|c|}
\hline & Categories & Request strategies & Examples \\
\hline \multirow{3}{*}{1} & \multirow{3}{*}{ Direct } & Obligation & You must/have to lend me your car \\
\hline & & Performative & I would like to ask you to lend me your car \\
\hline & & Imperative & Lend me your car (, please) \\
\hline \multirow{4}{*}{2} & \multirow{4}{*}{ Conventionally indirect (hearer-based) } & Ability & Can/could you lend me your car? \\
\hline & & Willingness & Would you lend me your car? \\
\hline & & Permission & May I borrow your car? \\
\hline & & Suggestory formula & How about lending me your car? \\
\hline \multirow{2}{*}{3} & \multirow{2}{*}{ Conventionally indirect (speaker-based) } & Wishes & I would like to borrow your car \\
\hline & & Desires/needs & I want/need to borrow your car \\
\hline 4 & Indirect & Hints & I have to be at the airport in half an hour \\
\hline
\end{tabular}

Salvesen (2015) compared Norwegian speakers and native speakers of English in a study on politeness strategies in requests. The aim was to see whether there was a pragmatic transfer of politeness strategies from the first language to the second language. The data was elicited by using role-play built on scenarios that emphasized different power relations, social distances, and costs of imposition. The findings suggested that politeness strategies can be transferred from the learners' first language to their target language.

Another study was conducted by Muthusamy and Farashaiyan (2016) on request, apology, and request mitigation strategies used by one hundred and thirty international postgraduate students specializing in different domains. The results showed that the participants used conventionally indirect expressions (preparatory questions) for requests more often than other expressions. Furthermore, social distance, power and imposition did not influence the participant choice of request strategies, but affected the use of mitigating strategies in different situations. Moreover, the results of the interviews suggested that students had encountered structural and lexical problems in performing of the speech acts.

Zarepour (2016), in a study of requesting strategies, mitigating elements and opening and closing strategies as well as supportive moves used in 61 e-mails sent by Iranian EFL learners to their professors, reported that because of the influence of L1 norms and culture, Iranian students tended to use more direct strategies. Furthermore, they tended to exercise mitigating elements and pre-request supportive moves to lessen the force of requests. In conclusion, there was a lack of pragmatic knowledge among Iranian EFL learners, and thus, they need to be observant of the norms of requestive e-mails written by native speakers of English.

\section{Speech Acts of Apology}

The speech act of apologizing involves of a group of strategies and sub-strategies and different writers have proposed frameworks to classify those strategies. Apology is defined as telling someone that you are sorry for having done something that has caused problems or unhappiness for them (Cambridge Online Dictionary, 2016).

Olshtain (1989: 156-7) defined an apology as "a speech act which is intended to provide support for the hearer who was actually or potentially malaffected by a violation". In an apology, the speaker is ready to degrade himself/ herself to a degree that the apology is a face-saving act for the hearer and a face-threatening act for the speaker.

Searle (1969) classified speech acts into five groups: assertives, directives, commissives, expressives, and declarations. Apologies come under expressive speech acts. For an apology to have an impact on the hearer, the speaker should be sincere and have true and honest feelings of sadness. There are three reasons for an apology: regret, responsibility and remedy. The apologizer should take the above mentioned points into account, otherwise the apology will not be sincere and effective (Engel, 2001).

The speech act of apology has certain elements (Brown and Attardo, 2000). These include:

1. Expressing of an apology, in which the speaker expresses feelings of regret, such as, "I am sorry".

2. Clarifying the situation, in which the apologizer attempts to reconstruct the incident for the victim in order to show that the forgiveness is deserved.

3. Admitting the mistake, in which the wrongdoer admits fault as a part of the apology.

4. Presenting repair.

5. Promising of nonrecurrence

Although the importance of the above elements was emphasized by Brown and Attardo (2000), sometimes it is enough to utter one word as an apology if it happens among close friends (Bataineh, 2004).

Most of the research carried out on English has concentrated on how different English language learners apologize. 
Table 2. Strategies for apology (Olshtain and Cohen, 1983)

\begin{tabular}{llll}
\hline \multicolumn{2}{c}{ Strategy } & & Example \\
\hline \multirow{2}{*}{1} & Expression of apology & Expression of regret & I'm sorry \\
\cline { 3 - 4 } & Offer of apology & Excuse me \\
\cline { 3 - 4 } & Request for forgiveness & Excuse me \\
\hline 2 & Explanation or account of the situation & & The bus was late \\
\cline { 3 - 4 } 3 & Acknowledgment of responsibility & Accepting the blame & It's my fault \\
\cline { 3 - 4 } & & Expressing self-deficiency & I wasn't thinking \\
\cline { 2 - 3 } & Recognizing the other person as deserving apology & You are right \\
\hline 4 & An offer of repair & I didn't mean to \\
\hline 5 & Promise of forbearance & I'll pay for the broken vase \\
\hline
\end{tabular}

Strategies used in apology are affected by different variables, like social differences and social status. Holmes (1995) stated in a study conducted in New Zealand that there were significant differences in expressing apology between males and females, and that females tended to apologize more.

It is obvious that the teaching of second language words and phrases without considering the sociocultural situation sometimes leads to linguistic ambiguities which in turn may lead to a communication breakdown. For example, the expression 'Sorry about that' is enough for an apology in some contexts, but not in others. It might be understood as impoliteness in some settings. Therefore, knowledge of speech act theory and training will support second language teachers in equipping their learners to overcome pragmatic competence problems (McKay and Hornberger, 1996). Apologies are clearly performative and expressive acts and by performing them, social ties are strengthened and sustained. All people to a large extent are aware of what comes after an apology and what is appropriate. The speakers who can express apology speech acts properly are considered as communicatively competent. Expressing apologies are important in everyday communication in order to sustain harmony. Thus, knowledge of the patterns of apologies and how to use them in different social situations is a significant skill (Wipprecht, 2006).

Khodareza and Lotfi (2013) carried out an experimental study of the effect of explicit pragmatic instruction on the development of interlanguage pragmatic competence of 60 Iranian advanced EFL learners' interpretation and use of the speech act of apology. They investigated whether formal instruction of pragmatic knowledge played a role in the enhancement of the advanced L2 learners' use and interpretation of the speech act of apology. The 60 Iranian advanced EFL learners were selected via administration of the Oxford Placement Test (OPT). Following the Martinez-Flor and Uso-Juan's 6R approach, the students were administered a pre-test of the apology speech act by the two researchers before completing 10 sessions of instruction on the targeted speech act. Two post-tests of the apology speech act were then administered and data were analysed via the paired sample T-test. The findings suggested that the advanced learners displayed improvement both in interpretation and in usage (Martinez-Flor and Uso-Juan, 2006).

The strategies of apology suggested by Olshtain and Cohen (1983) were used to analyse and code the speech act of apology in the current study, as shown in Table 2.

In the Kurdistan Region of Iraq, although the syllabi are based on communicative approaches from the early stages of the elementary level through to the university level, the students remain challenged in communicative competence. Passing the exams has become the main aim of English learning. Generally, the focus of learning and teaching is on the linguistic side of language and neglects the pragmatic aspect. It can be said that pragmatic competence is not given enough attention by teachers. It is not an uncommon phenomenon that an English learner can get high grades on an English test but does not know how to make a simple request in English in a real communication situation.

To have a deeper understanding of Kurdish EFL undergraduate student (KEFLUS) awareness of speech act conventions and pragmatic competence, the present research attempted to investigate the request and apology strategies and behavior of a group of Kurdish respondents in producing the speech acts in question. More specifically, the present research addressed the following questions:

1. What are the similarities and differences between KEFLUS and those of native speakers of English (NSE) with regard to overall request and apology strategy use and strategy patterns?

2. To what extent are KEFLUS able to choose the appropriate linguistic and pragmatic forms in performing the speech acts of request and apology?

3. Is there a significant difference between male and female KEFLUS in terms of overall strategy use and strategy patterns in the performance of the speech acts of request and apology and in the appropriate linguistic and pragmatic forms used? 
4. Is there a significant difference between private and state universities in terms appropriate linguistic and pragmatic forms of the speech acts of request and apology?

\section{METHOD}

\section{Participants}

Table 3. Number of participants in both groups

\begin{tabular}{cccc}
\hline Participants & Male & Female & Total \\
\hline Kurdish EFL Undergrad Students & 33 & 50 & 83 \\
\hline Native speakers of English & 3 & 11 & 14 \\
\hline Total & 36 & 61 & 97 \\
\hline
\end{tabular}

The subjects of the study were drawn from two groups: the first group consisted of 83 (33 male and 50 female) KEFLUS in Iraqi Kurdistan Region. They ranged in age from 19 to 24 years. The second group comprised 14 ( 3 male and 11 female) NSE with different academic degree. Three of the NSEs have a diploma, two bachelors, six masters, one $\mathrm{PhD}$, one honorary doctorate and one with no degree. While all the KEFLUS were university undergraduate students.

Table 4 shows a detailed description of the first group of KEFLUS participants. It is important to point out that the KEFLUS participant groups came from five state and private universities in the two cities of Erbil and Duhok in the Kurdistan region of Iraq.

Table 4. Kurdish EFL undergraduate students (KEFLUS)

\begin{tabular}{|c|c|c|c|c|c|c|c|c|c|c|}
\hline \multirow{2}{*}{ No. } & \multirow{2}{*}{ University } & \multirow{2}{*}{ College } & \multicolumn{4}{|c|}{ Stage } & \multicolumn{2}{|c|}{ Gender } & \multirow{2}{*}{ Age } & \multirow{2}{*}{ Number } \\
\hline & & & 1st & 2nd & 3rd & 4th & Male & Female & & \\
\hline 1 & Duhok & Arts & 6 & 8 & & & 6 & 8 & $19-24$ & 14 \\
\hline 2 & Salahaddin & languages & & & 11 & & 2 & 9 & $19-24$ & 11 \\
\hline 3 & Nawroz & Languages & & & 25 & & 11 & 14 & $19-24$ & 25 \\
\hline 4 & Soran & Arts & 2 & & 3 & 22 & 10 & 17 & $19-24$ & 27 \\
\hline 5 & Zakho & Arts & & & 6 & & 4 & 2 & $19-24$ & 6 \\
\hline Total & & & 8 & 8 & 45 & 22 & 33 & 50 & & 83 \\
\hline
\end{tabular}

The NSE participant group, on the other hand, came from different English-speaking countries including: the US, the UK, Canada and Ireland. The study used convenience sampling for the participants because both native and non-native participants were selected on the basis of their availability. As the procedure for the collection of the data from native speakers was more demanding and comparatively fewer native speakers were available or agreed to participate in the study, the number of non-native participants was greater than that of native speakers.

\section{Discourse Completion Test (DCT)}

There were six different conversational situations for the speech acts of request and apology. Participants were asked to imagine themselves in the described situations and to respond accordingly.

For most of the last decade, a diverse number of data collection methods have been applied in Pragmatics. Some form of questionnaire has been the dominant instrument for eliciting data in the past, particularly in cross-cultural and interlanguage pragmatics, and questionnaires are still considered to be the main instrument for data collection elicitation. Data-gathering tools are clustered into three types: interaction (authentic discourse, elicited conversation, role play), questionnaires (discourse completion, multiple-choice, scaled responses) and written and oral forms of self-reporting not based on questionnaires (diaries and verbal protocols). The three most extensively used kinds of questionnaire in pragmatics are discourse completion task (DCT), multiple choice and rating scale questionnaires (Spencer-Oatey, 2008).

The DCTS have been widely used in pragmatic studies. However, they have been criticized for some shortcomings, such as the fact that respondents have more time to answer the prompts. Moreover, it is argued that DCTs fail to gather information about nonverbal features, i.e., semiotics (Cohen, 1996).

In spite of these reservations, DCTs are a useful data elicitation tool in studies carried out in pragmatics (Beebe and Cummings, 1996; Nurani, 2009). They are easy to administer (Varghese and Billmyer, 1996) and provide the researcher with the opportunity to collect a large amount of data in quite a short time (Beebe and Cummings, 1996). 
Furthermore, the data collected by means of a DCT share some features with natural data and at least represent the main formulae and patterns of authentic conversation (ibid).

The present study employed a DCT in collecting the data. This form of DCT, consisting of six situations of request and apology and demographic information, is widely employed in cross-cultural and interlanguage pragmatics.

\section{Procedures}

The DCT consisted of six different situations for the speech acts of request and apology. These were translated into the Kurdish language (with both its dialects: Kurmanji and Sorani) and utilized as the data collection instrument. To ensure the validity of the instrument, it was piloted on six native speakers of English: five females and one male from different English-speaking countries (the US, Canada, the UK and Ireland) having various academic degrees (Diploma, BA and honorary doctorate). The participants were asked to answer the questions, mark any items whose wording they did not like, comment on any items whose meanings were not clear as well as mark any items which they considered unnecessary. Their comments were taken into consideration in revising the final version of the survey. The penultimate version of the DCT was constructed based on feedback from the initial pilot, but it was still not certain whether or not the respondents would answer without any difficulty in actual practice. Therefore, this DCT was administered to a group of 20 subjects from Duhok University College of Education Department of English Language, aged 22 -24 in a final pilot. This group of subjects was chosen for their similarity to the target population for the study. Finally, the DCT was administered to 83 Kurdish EFL university students and 14 native speakers of English.

\section{Data Analysis}

The present study aimed to investigate the speech acts of request and apology employed by the KEFLUS and NSE in terms of overall strategy use and strategy patterns as well as of sociolinguistic and pragmalinguistic competence. Data collected from participants were further analysed based on the analytical framework of BlumKulka et al.'s (1989) Cross-Cultural Speech Acts Realization Patterns (CCSARP) for request and Olshtain and Cohen's (1983) taxonomy for apology. The coding framework for requests distinguishes nine types of expressions classified into four main categories: direct, conventionally indirect (hearer-based), conventionally indirect (speakerbased) and indirect requests. A direct request is when there is direct and explicit relationship between the structure and function (e.g., 'Please open the door'). A conventional indirect request refers to "contextual preconditions necessary for its performance as conventionalized in the language" (Blum-Kulka et al., 1989. pp. 201-202) (e.g., 'Could you pass me the salt?'). An indirect request is expressed implicitly without referring directly to illocutionary force (e.g., 'I have to be at the airport in half an hour.'). Cohen (1996) states that a semantic formula may be "a word, phrase, or sentence that meets a particular semantic criterion or strategy; any one or more of these can be used to perform the act in question".

Descriptive statistics was used to examine the frequency of participants' overall strategy use and strategy patterns. To measure the appropriateness of the participants' responses pragmatically and linguistically, the elicited data was rated by four research assistants using a rating scale developed by the researcher with a five-point Likert scale ranging from 'entirely inappropriate' (one) to 'entirely appropriate' (five) used for questions posed to measure sociopragmatic competence and from 'strongly disagree' (one) to 'strongly agree' (five) used for questions posed to measure pragmalinguistic competence.

\section{RESULTS}

\section{First Research Question: What are the Similarities and Differences between KEFLUS and those of Native Speakers of English (NSE) with regard to Overall Request and Apology Strategy Use and Strategy Patterns?}

Table 5. Overall strategy used by the two groups (Request 1)

\begin{tabular}{ccc}
\hline Strategy & KEFLUS & NSE \\
\hline Direct & $22(26.5 \%)$ & $2(14.3 \%)$ \\
\hline Conventionally indirect (hearer-based) & $61(73.5 \%)$ & $6(42.9 \%)$ \\
\hline Conventionally indirect (speaker-based) & $0(0 \%)$ & $4(28.6 \%)$ \\
\hline Indirect & $0(0 \%)$ & $2(14.3 \%)$ \\
\hline Total & $83(100 \%)$ & $14(100 \%)$ \\
\hline
\end{tabular}


The findings of overall strategy used by KEFLUS and NSE to perform the first situation of the speech act of request are shown in Table 5. There is a difference between the two groups. The KEFLUS were more direct and explicit (26.5\%) than the NSE (14.3\%). The KEFLUS used conventionally indirect (hearer-based) strategies the most, while the NSE chose all strategies (direct, conventionally indirect (hearer-based), conventionally indirect (speakerbased) and indirect strategies) to request. However, both groups used conventionally indirect (hearer-based) strategies the most (KEFLUS: 73.5\%; NSE: 42.9\%). On the other hand, the KEFLUS used direct strategy the second most often (26.5\%), while the NSE utilized conventionally indirect (speaker-based) the second most often (28.6\%).

Table 6 illustrates the frequency and percentage of each individual strategy used by the two groups in performing the first situation of request. The KEFLUS tended to use more strategies of ability ('Can/could you ...?'), but the NSE preferred the strategy of wishing ('I would like ...') more often than the others.

Table 6. Individual strategies used by the two groups (Request 1)

\begin{tabular}{ccc}
\hline Strategy & KEFLUS & NSE \\
\hline Direct & & $1(7.1 \%)$ \\
\hline Obligation & $1(1.2 \%)$ & $2(14.3 \%)$ \\
\hline Performatives & $15(18.1 \%)$ & $0(0 \%)$ \\
\hline Imperatives & $5(6.0 \%)$ & \\
\hline Conventionally indirect (hearer-based) & & $2(14.3 \%)$ \\
\hline Ability & $51(61.4 \%)$ & $1(7.10 \%)$ \\
\hline Willingness & $5(6.0 \%)$ & $2(14.3 \%)$ \\
\hline Permission & $6(7.2 \%)$ & $1(7.1 \%)$ \\
\hline Suggestory formula & $0(0 \%)$ & $4(28.6 \%)$ \\
\hline Conventionally indirect (speaker-based) & & $1(7.1 \%)$ \\
\hline Wishes & $0(0 \%)$ & $14(100 \%)$ \\
\hline Indirect & &
\end{tabular}

Table 7 shows the overall strategy used by the KEFLUS and NSE to perform in the second situation of the speech act of request. Both groups of participants (KEFLUS and NSE) chose conventionally indirect (hearer-based) strategies the most (KEFLUS: $83.1 \%$; NSE: $71.4 \%$ ). The findings suggested that the KEFLUS group exhibited more directive and explicit behavior in interacting with interlocutors than the NSE.

Table 7. Overall strategy (Request 2)

\begin{tabular}{ccc}
\hline Strategy & KEFLUS & NSE \\
\hline Direct & $14(16.9 \%)$ & $1(7.1 \%)$ \\
\hline Conventionally indirect (hearer-based) & $69(83.1 \%)$ & $10(71.4 \%)$ \\
\hline Conventionally indirect (speaker-based) & $0(0 \%)$ & $3(21.4 \%)$ \\
\hline Total & $83(100 \%)$ & $14(100 \%)$ \\
\hline
\end{tabular}

Table 8 illustrates the results of the strategy used by each individual of the two groups in performing in the second situation of the speech act of request. The KEFLUS group tended to use the strategy of ability ('Can/ Could you ...?') the most $(74.7 \%)$ and the imperative ('Give me the lecture notes') the second most often $(9.6 \%)$ than the other strategies. Similarly, the NSE favoured the strategy of ability ('Can/ Could you ...?') the most (35.7\%).

Table 8. Individual strategy by the two groups (Request 2)

\begin{tabular}{ccc}
\hline Strategy & KEFLUS & NSE \\
\hline Direct & & \\
\hline Performative & $7(8.4 \%)$ & $1(7.1 \%)$ \\
\hline Imperative & $8(9.6 \%)$ & $0(0 \%)$ \\
\hline Ability & & $5(35.7 \%)$ \\
\hline Willingness & $62(74.7 \%)$ & $1(7.1 \%)$ \\
\hline Permission & $5(6.0 \%)$ & $3(21.4 \%)$ \\
\hline Suggestory formula & $1(1.2 \%)$ & $1(7.1 \%)$ \\
\hline Conventionally indirect (hearer-based) & $0(0 \%)$ & $3(21.4 \%)$ \\
\hline Wishes & & $14(100 \%)$ \\
\hline Total & $0(0 \%)$ &
\end{tabular}


Table 9 shows the overall strategy used by the KEFLUS and NSE to perform in the third situation of the speech act of request. The results indicated that there was similarity in the requestive behavior of both groups of respondents. The most favoured strategy utilized by the KEFLUS was conventionally indirect (hearer-based) $(91.6 \%)$ and direct strategies came second (8.4\%). The NSE used conventionally indirect (hearer-based) strategies the most $(92.9 \%)$. However, the KEFLUS had more of a tendency to use indirect strategies $(7.1 \%)$.

Table 9. Overall strategy used by the two groups (Request 3)

\begin{tabular}{ccc}
\hline Strategy & KEFLUS & NSE \\
\hline Direct & $7(8.4 \%)$ & $0(0 \%)$ \\
\hline Conventionally indirect (hearer-based) & $76(91.6 \%)$ & $13(92.9 \%)$ \\
\hline Indirect & $0(0 \%)$ & $1(7.1 \%)$ \\
\hline Total & $83(100 \%)$ & $14(100 \%)$ \\
\hline
\end{tabular}

Table 10 illustrates the strategy used by the two groups in performing in the third situation of the speech act of request. The results showed that the most frequent type utilized by both the KEFLUS and NSE was the ability strategy, which accounted for $83.1 \%$ in the KEFLUS compared with $57.1 \%$ in the NSE. However, the KEFLUS were more direct and explicit in their requestive behavior than the NSE.

Table 10. Individual strategy by the two groups (Request 3)

\begin{tabular}{ccc}
\hline Strategy & KEFLUS & NSE \\
\hline Direct & & $0(0 \%)$ \\
\hline Performative & $6(7.2 \%)$ & $0(0 \%)$ \\
\hline Imperative & $2(2.4 \%)$ & \\
\hline Conventionally indirect (hearer-based) & & $8(57.1 \%)$ \\
\hline Ability & $69(83.1 \%)$ & $3(21.4 \%)$ \\
\hline Willingness & $6(7.2 \%)$ & $2(14.3 \%)$ \\
\hline Permission & $0(0 \%)$ & $1(7.1 \%)$ \\
\hline Indirect & & $14(100 \%)$
\end{tabular}

Table 11 illustrates that the most favoured formulae for the KEFLUS in expression of apology (consecutively) were: Illocutionary Force Indicating Device + an account of explanation (IFID + EXPL) (67.5\%), an account of explanation (EXPL)(18.1\%), Illocutionary Force Indicating Device + an account of explanation + an offer of repair (IFID+EXPL+REPR) (9.6\%), Illocutionary Force Indicating Device + an offer of repair (IFID+REPR) (3.6\%), and Illocutionary Force Indicating Device + acknowledging responsibility (IFID+RESP) $(1.2 \%)$.

Table 11. Individual strategy by the two groups (Apology1)

\begin{tabular}{ccc}
\hline Strategy & KEFLUS & NSE \\
\hline IFID & $15(18.1 \%)$ & $0(0 \%)$ \\
\hline IFID \& EXPL & $56(67.5 \%)$ & $7(50.0 \%)$ \\
\hline IFID + REPR & $3(3.6 \%)$ & $1(7.1 \%)$ \\
\hline IFID + RESP & $1(1.2 \%)$ & $0(0 \%)$ \\
\hline IFID + EXPL + REPR & $8(9.6 \%)$ & $6(42.9 \%)$ \\
\hline Total & $83(100 \%)$ & $14(100 \%)$ \\
\hline
\end{tabular}

On the other hand, the favoured apology formulae for the NSE were Illocutionary Force Indicating Device + an account of explanation (IFID+EXPL) (50.0\%) and Illocutionary Force Indicating Device + an account of explanation + an offer of repair (IFID+EXPL+REPR) (42.9\%).

Table 12. Individual strategy by the two groups (Apology 2)

\begin{tabular}{ccc}
\hline Strategy & KEFLUS & NSE \\
\hline IFID & $44(53.0 \%)$ & $5(35.7 \%)$ \\
\hline IFID \& EXPL & $37(44.6 \%)$ & $9(63.3 \%)$ \\
\hline IFID + REPR & $1(1.2 \%)$ & $0(0 \%)$ \\
\hline IFID + RESP & $1(1.2 \%)$ & $0(0 \%)$ \\
\hline Total & $83(100 \%)$ & $14(100 \%)$ \\
\hline
\end{tabular}


To elaborate, as presented in Table 12, out of the total of 83 KEFLUS, 44 (53\%) included the use of a direct apology offered via an apology reformative verb (an IFID expression). The second most frequent apology strategy offered among the KEFLUS was an apology reformative verb (IFID expression) followed by an account of explanation (EXPL) 37 (44.6\%). In contrast, out of the 14 NSE, nine $(63.3 \%)$ used an apology reformative verb and an account of explanation (IFID+EXPL) and five participants (35.7 \%) favoured an apology reformative verb (IFID expression).

The KEFLUS used different manifestations of apology strategies as shown in Table 13. The majority of respondents $(68,81.9 \%)$ used an expression of apology (IFID) and an account of explanation (EXPL). Out of the total 83 KEFLUS, only 13 (15.7\%) used an expression of apology (IFID). On the other hand, the most frequent apology formula among the NSE was an expression of apology (IFID) and an account of explanation (EXPL) -- (IFID + EXPL) (78.6\%). Furthermore, the second preference of the NSE was an expression of apology, an account of explanation and an offer of repair (IFID + EXPL + REPR) $(14.3 \%)$.

Table 13. Individual strategy by the two groups (Apology 3)

\begin{tabular}{ccc}
\hline Strategy & KEFLUS & NSE \\
\hline IFID & $13(15.7 \%)$ & $0(0 \%)$ \\
\hline IFID \& EXPL & $68(81.9 \%)$ & $11(78.6 \%)$ \\
\hline IFID + RESP & $1(1.2 \%)$ & $0(0 \%)$ \\
\hline IFID + EXPL + REPR & $1(1.2 \%)$ & $2(14.3 \%)$ \\
\hline IFID + EXPL + RESP & $0(0 \%)$ & $1(7.1 \%)$ \\
\hline Total & $83(100 \%)$ & $14(100 \%)$ \\
\hline
\end{tabular}

\section{Second Research Question: To what extent are KEFLUS able to Choose the Appropriate Linguistic and Pragmatic Forms in Performing the Speech Acts of Request and Apology?}

The second research question was divided into two sub-questions or parts. The first touched the functional aspect of language or pragmatics (sociopragmatics): Is the participant's response pragmatically (sociopragmatically) appropriate? while the second part or sub-question covered the linguistic side of language, or the form (pragmalinguistics): Is the participant's response grammatically or structurally (pragmalinguistically) correct?

To answer these two sub-questions, four qualified and experienced research assistants rated the KEFLUS responses according to a rating scale developed by the researcher with a five-point Likert scale ranging from 'entirely inappropriate' (one) to 'entirely appropriate' (five) for the first sub-question and 'strongly disagree '(one) to 'strongly agree '(five) for the second sub-question.

Table 14. Speech act of request (sociopragmatics)

\begin{tabular}{|c|c|c|c|c|c|}
\hline & Questior & & Request 1 & Request 2 & Request 3 \\
\hline \multirow{4}{*}{ Pragmatic } & \multirow{2}{*}{$\mathrm{N}$} & Valid & 332 & 332 & 332 \\
\hline & & Missing & 0 & 0 & 0 \\
\hline & \multicolumn{2}{|c|}{ Mean } & 2.9970 & 3.0060 & 3.2651 \\
\hline & \multicolumn{2}{|c|}{ Std. Deviation } & 1.01796 & .96461 & 1.07242 \\
\hline
\end{tabular}

Table 15. Speech act of apology (sociopragmatics)

\begin{tabular}{|c|c|c|c|c|c|}
\hline & Question & & Apology1 & Apology 2 & Apology 3 \\
\hline \multirow{4}{*}{ Pragmatic } & \multirow{2}{*}{$\mathrm{N}$} & Valid & 332 & 332 & 332 \\
\hline & & Missing & 0 & 0 & 0 \\
\hline & \multicolumn{2}{|c|}{ Mean } & 3.2620 & 3.3494 & 3.2620 \\
\hline & \multicolumn{2}{|c|}{ Std. Deviation } & 1.04318 & 1.10406 & 1.04896 \\
\hline
\end{tabular}

Regarding the first question in the rating scale, Tables 14 and $\mathbf{1 5}$ show the mean and standard deviation of the respondents' pragmatic performances of the speech acts of request and apology. The findings suggested that there was a slight difference between the mean scores of the responses in the three situations of request and apology. Furthermore, the participants faced more difficulty in performing the first situation of request than they did in the second and third. The respondents were generally able to realize the speech acts of request and apology functionally and structurally. 
Table 16. Speech act of request (pragmalinguistics)

\begin{tabular}{cccccc}
\hline Question & & & Request 1 & Request 2 & Request 3 \\
\hline \multirow{3}{*}{ Grammar } & \multirow{2}{*}{$N$} & Valid & 332 & 332 & 332 \\
\cline { 2 - 5 } & & Missing & 0 & 0 & 0 \\
\cline { 2 - 5 } & \multicolumn{2}{c}{ Mean } & 3.1566 & 3.0879 & 3.2651 \\
\cline { 2 - 5 } & \multicolumn{2}{c}{ Std. Deviation } & 1.02809 & 1.05826 & 1.12735 \\
\hline
\end{tabular}

Table 17. Speech act of apology (pragmalinguistics)

\begin{tabular}{cccccc}
\hline Question & & & Apology1 & Apology 2 & Apology 3 \\
\hline \multirow{3}{*}{ Grammar } & \multirow{2}{*}{$\mathrm{N}$} & Valid & 332 & 332 & 332 \\
\cline { 2 - 5 } & & Missing & 0 & 0 & 0 \\
\cline { 2 - 5 } & \multicolumn{2}{c}{ Mean } & 3.1566 & 3.2380 & 3.1596 \\
\cline { 2 - 5 } & \multicolumn{2}{c}{ Std. Deviation } & 1.03102 & 1.10232 & .99324 \\
\hline
\end{tabular}

With regard to the second question posed in the rating scale, Tables 16 and 17 show the descriptive statistics of the respondents' performances of the speech acts of request and apology as rated by the four researchers.

The findings indicated that there was a remarkable similarity between the mean scores of each of the three situations of request and apology. The participants faced more challenges in responding to the second and first than they did in the third situation of request, and in the second situation of apology than they did in the third. According to the mean scores of both request and apology, the participant responses were generally appropriate.

\section{Third Research Question: Is there a Significant Difference between Male and Female KEFLUS in terms of Overall Strategy Use and Strategy Patterns in the Performance of the Speech Acts of Request and Apology and in the Appropriate Linguistic and Pragmatic Forms Used?}

\section{The speech act of request}

Tables 18, 19 and 20 display the frequency and percentage of each type of strategy utilized by Kurdish EFL male and female respondents in the three situations of request. There were some differences among the participants based on the explicitness of the request. The results suggested that males had used more explicit and direct strategies of request, while females had more of a tendency to use inexplicit and indirect strategies. This indicated that the females had politer requestive behavior than males. However, both female and male Kurdish EFL students used indirect strategies the most, followed by direct strategies second. This coincided with the findings of previous studies that have presented gender as an important factor in the use of speech acts in general (Lukasik, 2000).

Table 18. Request 1

\begin{tabular}{ccc}
\hline Strategy & Male & Female \\
\hline Direct & & $0(0 \%)$ \\
\hline Obligation & $1(2.8 \%)$ & $7(14.0 \%)$ \\
\hline Performative & $8(24.2 \%)$ & $3(6.0 \%)$ \\
\hline Imperative & $2(6.1 \%)$ & \\
\hline Ability & & $33(66.0 \%)$ \\
\hline Willingness & $18(54.5 \%)$ & $3(6.0 \%)$ \\
\hline Permission & $2(6.1 \%)$ & $4(8.0 \%)$ \\
\hline Total & $2(6.1 \%)$ & $50(100 \%)$ \\
\hline
\end{tabular}


Table 19. Request 2

\begin{tabular}{ccc}
\hline Strategy & Male & Female \\
\hline Direct & & $3(6.0 \%)$ \\
\hline Performative & $4(12.1 \%)$ & $2(4.0 \%)$ \\
\hline Imperative & $6(18.2 \%)$ & \\
\hline $\begin{array}{c}\text { Conventionally indirect } \\
\text { (hearer-based) }\end{array}$ & & $41(82.0 \%)$ \\
\hline Ability & $21(63.6 \%)$ & $4(8.0 \%)$ \\
\hline Willingness & $1(3.0 \%)$ & $0(0 \%)$ \\
\hline Permission & $1(3.0 \%)$ & $50(100 \%)$ \\
\hline Total & $33(100 \%)$ & \\
\hline
\end{tabular}

Table 20. Request 3

\begin{tabular}{ccc}
\hline Strategy & Male & Female \\
\hline Direct & & \\
\hline Performative & $4(12.1 \%)$ & $2(4.0 \%)$ \\
\hline Imperative & $2(6.1 \%)$ & $0(0 \%)$ \\
\hline Conventionally indirect (hearer-based) & & \\
\hline Ability & $25(75.8 \%)$ & $44(88.0 \%)$ \\
\hline Willingness & $2(6.1 \%)$ & $4(8.0 \%)$ \\
\hline Total & $33(100 \%)$ & $50(100 \%)$ \\
\hline
\end{tabular}

Table 21. Independent Samples t-test

\begin{tabular}{cccccc}
\hline & Gender & N & Mean & Std. Deviation & Sig. (2-tailed) \\
\hline \multirow{2}{*}{ Request 1 } & male & 264 & 3.0152 & 1.01685 & .208 \\
\cline { 2 - 6 } & female & 400 & 3.1175 & 1.03022 & .045 \\
\hline \multirow{2}{*}{ Request 2 } & male & 264 & 2.9432 & 1.02469 & .280 \\
\cline { 2 - 6 } & female & 400 & 3.1050 & 1.00822 & 1.16596 \\
\hline \multirow{2}{*}{ Request 3 } & male & 264 & 3.2083 & 1.05298 & \\
\cline { 2 - 6 } & female & 400 & 3.3025 & & \\
\hline
\end{tabular}

As seen above, the t-test was used to compare the mean scores of the male and female participants. Table 21 shows the appropriate linguistic and pragmatic forms of the speech act of request as rated by the four researchers according to the scale developed by the researcher. The findings indicated that there was a statistically significant difference between the two groups (males and females) in the second situation for the speech act of request. Furthermore, there was a difference between males and females for the two other situations of request (first and third); however, these were not statistically significant. The groups were similar to each other in their use of request strategies for the first and third situations. The findings indicated that the females showed more sociopragmatic and pragmalinguistic competence than the males in performing and realizing the speech acts of request.

\section{The speech act of apology}

Table 22. Individual strategy by the two groups (Apology1)

\begin{tabular}{ccc}
\hline Strategy & Male & Female \\
\hline Direct & & \\
\hline IFID & $6(18.2 \%)$ & $9(18.0 \%)$ \\
\hline IFID \& EXPL & $22(66.7 \%)$ & $34(68.0 \%)$ \\
\hline IFID \& PERP & $2(6.1 \%)$ & $1(2.0 \%)$ \\
\hline IFID + RESP & $1(3.0 \%)$ & $0(0 \%)$ \\
\hline IFID + EXPL + REPR & $2(6.1 \%)$ & $0(0 \%)$ \\
\hline IFID + EXPL + RESP & $0(0 \%)$ & $6(12.0 \%)$ \\
\hline Total & $33(100 \%)$ & $50(100 \%)$ \\
\hline
\end{tabular}


Table 23. Individual strategy by the two groups (Apology 2)

\begin{tabular}{ccc}
\hline Strategy & Male & Female \\
\hline Direct & & \\
\hline IFID & $17(51.5 \%)$ & $27(54.0 \%)$ \\
\hline IFID \& EXPL & $16(48.5 \%)$ & $21(42.0 \%)$ \\
\hline IFID \& PERP & $0(0 \%)$ & $1(2.0 \%)$ \\
\hline IFID + RESP & $0(0 \%)$ & $1(2.0 \%)$ \\
\hline Total & $33(100 \%)$ & $50(100 \%)$ \\
\hline
\end{tabular}

Table 24. Individual strategy by the two groups (Apology 3)

\begin{tabular}{ccc}
\hline Strategy & Male & Female \\
\hline Direct & & \\
\hline IFID & $5(15.2 \%)$ & $8(16.0 \%)$ \\
\hline IFID \& EXPL & $27(81.8 \%)$ & $41(82.0 \%)$ \\
\hline IFID + RESP & $1(3.0 \%)$ & $0(0 \%)$ \\
\hline IFID + EXPL + REPR & $0(0 \%)$ & $1(2.0 \%)$ \\
\hline Total & $33(100 \%)$ & $50(100 \%)$ \\
\hline
\end{tabular}

Tables 22, 23 and 24 illustrate the different apology strategies used by the KEFLUS males and females. A slight difference was noticed between the males and females. The females used more apology strategies than the males, which coincided with the findings of the study conducted by Holmes (1995) which suggested that women used more apologies than men. However, there was a remarkably similarity in frequencies between some of the apology strategies used by the male and female respondents. Both used IFID + EXPL the most in the first and third situations of apology, followed by IFID the second most often. Moreover, they used IFID the most in the second situation of apology, followed by IFID + EXPL.

Table 25. Independent samples t-test

\begin{tabular}{|c|c|c|c|c|c|}
\hline & Gender & $\mathbf{N}$ & Mean & Std. Deviation & Sig. (2-tailed) \\
\hline \multirow{2}{*}{ Apology 1} & Male & 264 & 3.1780 & .98396 & \multirow{2}{*}{.0528} \\
\hline & Female & 400 & 3.2300 & 1.07237 & \\
\hline \multirow{2}{*}{ Apology 2} & Male & 264 & 3.2348 & 1.07059 & \multirow{2}{*}{.265} \\
\hline & Female & 400 & 3.3325 & 1.12477 & \\
\hline \multirow{2}{*}{ Apology 3} & Male & 264 & 3.2008 & 1.03615 & \multirow{2}{*}{.0837} \\
\hline & Female & 400 & 3.2175 & 1.01379 & \\
\hline
\end{tabular}

The t-test analysis (Table 25) revealed that there was no significant difference between the males and females in terms of strategies used to apologize. This finding is similar to that of Juhana (2011), who reported no significant differences between male and female postgraduate students of English Education in using apologizing strategies.

\section{Fourth Research Question: Is there a Significant Difference between Private and State Universities in terms Appropriate Linguistic and Pragmatic Forms of the Speech Acts of Request and Apology?}

Table 26. Independent samples t-test of the speech acts of request

\begin{tabular}{|c|c|c|c|c|c|}
\hline & Type of University & $\mathbf{N}$ & Mean & Std. Deviation & Sig. (2-tailed) \\
\hline \multirow{2}{*}{ Request 1} & State & 464 & 3.0496 & 1.04112 & \multirow{2}{*}{.297} \\
\hline & Private & 200 & 3.1400 & .98756 & \\
\hline \multirow{2}{*}{ Request 2} & State & 464 & 2.9892 & 1.02553 & \multirow{2}{*}{.047} \\
\hline & Private & 200 & 3.1600 & .98959 & \\
\hline \multirow{2}{*}{ Request 3} & State & 464 & 3.1810 & 1.13533 & \multirow{2}{*}{.003} \\
\hline & Private & 200 & 3.4600 & .98654 & \\
\hline
\end{tabular}


Table 27. Independent samples t-Test of the speech acts of apology

\begin{tabular}{|c|c|c|c|c|c|}
\hline & Type of University & $\mathbf{N}$ & Mean & Std. Deviation & Sig. (2-tailed) \\
\hline \multirow{2}{*}{ Apology1 } & state & 464 & 3.1530 & 1.04141 & \multirow{2}{*}{.033} \\
\hline & private & 200 & 3.3400 & 1.01961 & \\
\hline \multirow{2}{*}{ Apology 2} & state & 464 & 3.1552 & 1.13346 & \multirow{2}{*}{.000} \\
\hline & private & 200 & 3.6150 & .95989 & \\
\hline \multirow{2}{*}{ Apology 3} & state & 464 & 3.0625 & 1.04457 & \multirow{2}{*}{.000} \\
\hline & private & 200 & 3.5550 & .87797 & \\
\hline
\end{tabular}

Regarding the fourth research question, the four researchers rated the responses of the speech acts of request and apology in terms of appropriate linguistic form and pragmatic function. Tables 26 and 27 display the $t$-test analysis used to compare the mean scores of the respondents studying at both state and private universities. The results revealed that there was a significant difference between state and private universities. Private university respondents showed more competence than those at state universities.

\section{CONCLUSION}

The functional aspect of the language is becoming more important than ever. Moreover, the meaning is as important as the form in language acquisition. The current study aimed to investigate the interlanguage pragmatic competence of the KEFLUS. A DCT was designed and used to elicit the required data. The data were coded according to a revised scheme, and then were analysed in terms of perception of overall strategy use, strategy patterns and sociopragmatic and pragmalinguistic competence. In addition, the existence of any significant differences between males and females and state and private universities was explored. The results showed that the majority of the KEFLUS and NSE had a tendency to utilize conventional indirect request strategy. This finding is similar to the results of the interlanguage studies of Byon (2004), Rue and Martino (2007), and Khorshidi and Subbakrishna (2013), and contrary to the study of Zarepour (2016), which indicated that the participants used more direct strategies. Furthermore, the KEFLUS tended to utilize direct and explicit request strategies more than the NSE. This study indicated that the responses of the KEFLUS were generally linguistically and pragmatically appropriate, which contrasts with the results of the study carried out by El Hiani (2015). His study revealed that Moroccan EFL learners failed to appropriately produce the speech acts of apologizing, inviting, congratulating, adding information, complimenting, introducing, greeting, expressing gratitude, refusing, helping, making suggestions, requesting, offering, criticizing, and complaining. Differences in the use of apology strategies were found to occur not only between the KEFLUS and NSE but also between the male and female KEFLUS, in other words, within the same culture, and different apology strategies within the same culture have been reported to cause problems for ESL/EFL learners (Bataineh and Bataineh, 2008).

\section{Pedagogical Implications}

Language and culture are closely related. Therefore, teaching a foreign language is inseparable from teaching its cultural and social norms. Hopefully, the findings of this study will help EFL/ ESL teachers to pay more attention to pragmatic knowledge and raise student awareness of English socio-cultural norms of speech act realizations.

\section{REFERENCES}

Achiba, M. (2003). Learning to Request in a Second Language. Clevedon, UK: Multilingual Matters.

Apology. (2016). In Cambridge online dictionary. Retrieved July 2, 2016, from http://dictionary.cambridge.org/dictionary/english/apologize

Austin, J. L. (1962). How to Do Things with Words. Oxford: Clarendon Press.

Austin, J. L. (1965). How to Do Things with Words. Oxford: Clarendon Press.

Austin, J. L. (1975). How to Do Things with Words. Cambridge, Massachusetts: Harvard University Press.

Bataineh, R. F., \& Bataineh, R. F. (2008). A cross-cultural comparison of apologies by native speakers of American English and Jordanian Arabic. Journal of Pragmatics 40(4), 792-821.

Bataineh, R. F. (2004). A cross-cultural study of the speech act of apology in American English and Jordanian Arabic (Unpublished Ph.D. dissertation). Indiana, Pennsylvania: Indiana University of Pennsylvania. 
Beebe, L., \& Cummings, M. (1996). Natural speech act data versus written questionnaire data: How data collection method affects speech act performance. In: Gass, S., Neu, J. (Eds.), Speech Acts across Cultures: Challenges to Communication in a Second Language. Berlin/ New York: Mouton de Gruyter, pp. 65- 88.

Blum-Kulka, S., \& Olshtain, E. (1984). Requests and apologies: A cross cultural study of speech act realization patterns (CCSARP). Applied Linguistics 5, 196-213.

Blum-Kulka, S., House, J., \& Kasper, G. (1989). Cross-cultural Pragmatics: Requests and Apologies. Norwood, NJ: Alblex Publishing Corporation.

Brown, P., \& Levinson, S. (1978). Universals in language usage: Politeness phenomena. In: Goody, E. (Ed.), Questions and Politeness: Strategies in Social Interaction. Cambridge: Cambridge University Press, pp. 56-310.

Brown, P., \& Levinson, S. (1987). Politeness: Some Universals in Language Usage. Cambridge: Cambridge University Press.

Brown, S., \& Attardo, S. (2000). Understanding Language Structure, Interaction and Variation: An Introduction to Applied Linguistics and Sociolinguistics for Nonspecialists. Ann Arbor: University of Michigan Press.

Byon, A. S. (2004). Sociopragmatic analysis of Korean requests: Pedagogical setting. Journal of Pragmatics, 36, 19731704.

Clark, H. (1979). Responding to Indirect Speech Acts. Cognitive Psychology, 11, 430-477.

Cohen, A. (1996). Developing the ability to perform speech acts. SSLA, 18, 253-267.

El Hiani, K. (2015). Performing speech acts among Moroccan EFL advanced learners. Procedia - Social and Behavioral Sciences, 199, 479 - 485.

Engel, B. (2001). The Power of Apology: Healing Steps to Transform All Relationships. New York: John Wiley \& Sons.

Hatch, E. (1992). Discourse and Language Education. Cambridge: Cambridge University Press.

Holmes, J. (1995). Women, Men and Politeness. London: Longman.

Holtgraves, T. (1986). Language structure in social interaction: Perceptions of direct and indirect speech acts and interactants who use them. Journal of Personality and Social Psychology 51(2), 305-14.

House, J., \& Kasper, G. (1987). Interlanguage pragmatics: Requesting in a foreign language. In: Lörsche, W. Schulze, R. (Eds.), Perspectives on Language in Performance (Vol. 2,). Tübingen, Germany: Narr, pp. 1250-1288.

Jia, Y. (2007). Pragmatic diversity, pragmatic transfer, and cultural identity. Intercultural Communication Studies 16(2), 37-54.

Juhana. (2011). The use of apologizing speech acts realization by male and female students: A case study in the postgraduate program of the English Education Department. Ragam Jurnal Pengembangan Humaniora, 11(1), $1-10$.

Kecskes, I. (2014). Intercultural pragmatics. New York: Oxford University Press.

Khodareza, M., \& Lotfi, A. R. (2013). Interlanguage pragmatic development: The effect of formal instruction on Iranian EFL learners' interpretation and use of speech act of apology. Asian Journal of Social Sciences and Humanities 2(2), 99-104.

Khorshidi, H. R., \& Subbakrishna, R. (2013). Request strategy development in Iranian study abroaders. International Journal of Applied Linguistics \& English Literature, 2(6), 129-142.

Lukasik, V. J. (2000). Predictors of the willingness to use forgiveness as a coping strategy in adolescent friendships (Unpublished Ph.D. Dissertation). Detroit, Michigan: Wayne State University.

Martinez-Flor, A., \& Uso-Juan, E. (2006). Pragmatic development in a second or foreign language: Some classroom techniques. Greta 14(1 \& 2), 50-56.

McKay, S., \& Hornberger, N., H. (1996). Sociolinguistics and Language Teaching. Cambridge: Cambridge University Press.

Muthusamy, P., \& Farashaiyan, A. (2016). Situational variations in request and apology realization strategies among International postgraduate students at Malaysian universities. English Language Teaching 9(3), 181-196.

Nurani, L. M. (2009). Methodological issues in pragmatic research: Is the discourse completion test a reliable data collection instrument? J. Sosioteknologi Ed., 17(8), 667-678.

Olshtain, E. (1989). Apologies across cultures. In: Blum-Kulka, S., House, J., Kasper, G. (Eds.), Cross-Cultural Pragmatics: Requests and Apologies. Norwood, NJ: Albex.

Olshtain, E., \& Cohen, A. D. (1983). Apology: A speech-act set. In: Wolfson, N., Judd, E. (Eds.), Sociolinguistics and Language Acquisition. Rowley, MA: Newbury House, pp. 18-35. 
Rue, H., \& Martino, S. (2007). Approximate Bayesian inference for hierarchical Gaussian Markov random fields models. Journal of Statistical Planning and Inference. Special Issue: Bayesian Inference for Stochastic Processes 137(10), 3177-3192.

Salvesen, K. E. (2015). Politeness strategies in requests by Norwegian learners of English in comparison with native speakers of English. Hawaii Pacific University TESOL Working Paper Series, 13, 53-69.

Searle, J. R. (1969). Speech Acts: An Essay in the Philosophy of Language. Cambridge: Cambridge University Press.

Searle, J. R. (1976). A classification of illocutionary acts. Language in Society 5, 1-23.

Searle, J. R., Kiefer, F., \& Bierwisch, M. (Eds.). (1980). Speech Act Theory and Pragmatics. London: D. Reidel Publishing Company.

Spencer-Oatey, H. (2008). Culturally Speaking: Culture, Communication and Politeness Theory, Second edition. London/New York: Continuum International Publishing Group.

Thomas, J. (1983). Cross-cultural pragmatic failure. Applied Linguistics, 4, 91-11.

Trosborg, A. (1995). Interlanguage Pragmatics: Requests, Complaints and Apologies. Berlin: Mouton de Gruyter.

Varghese, M., \& Billmyer, K. (1996). Investigating the structure of discourse completion test. Work. Pap. Educ. Linguistics, 12(1), 39-58.

Wipprecht, C. (2006). The Speech Act of Apology in an American Soap Opera and the German Equivalent. Munich: GRIN Verlag.

Zarepour, F. (2016). An analysis of Iranian EFL learners' English written requestive E mails. Journal of Language Teaching and Research, 7(3), 579-585.

\section{http://www.ejmste.com}

